Document downloaded from:

http://hdl.handle.net/10251/105841

This paper must be cited as:

Carrillo Abad, J.; García Gabaldón, M.; Pérez-Herranz, V. (2017). pH effect on zinc recovery from the spent pickling baths of hot dip galvanizing industries. Separation and Purification Technology. 177:21-28. doi:10.1016/j.seppur.2016.12.034

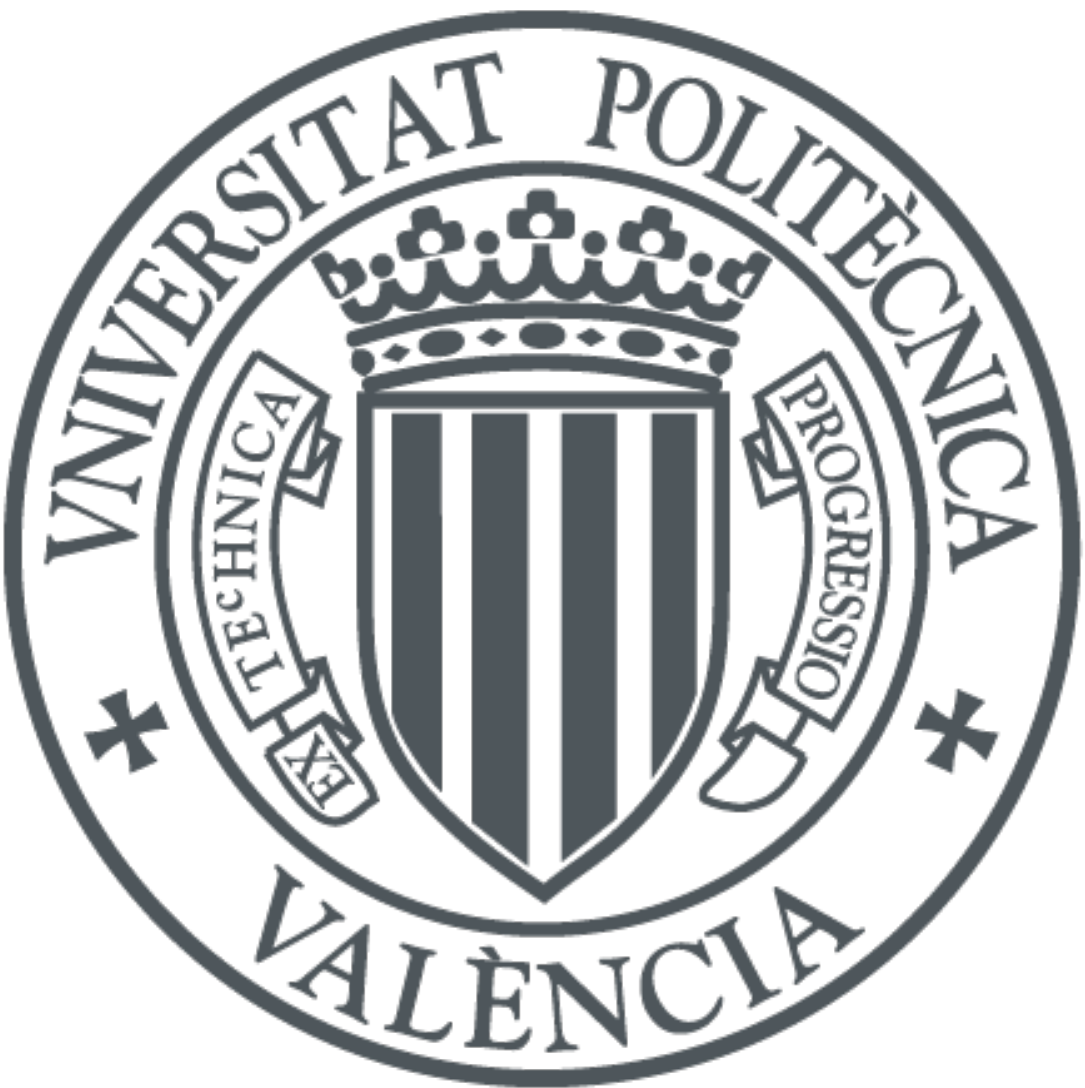

The final publication is available at

http://doi.org/10.1016/j.seppur.2016.12.034

Copyright Elsevier

Additional Information 


\title{
pH effect on zinc recovery from the spent pickling baths of hot dip galvanizing industries
}

\author{
J. Carrillo-Abad, M. García-Gabaldón*, V. Pérez-Herranz \\ Departamento de Ingeniería Química y Nuclear, Universidad Politécnica de Valencia, P.O. Box 22012, \\ E-46023 Valencia, España.
}

${ }^{*}$ Correspondence to: Departamento de Ingeniería Química y Nuclear, Universidad Politécnica de Valencia, P.O. Box 22012, E-46023 Valencia, España.

E-mail: mongarga@iqn.upv.es; Phone: +34 963877007 ext. 76313; Fax: +34 963879632 


\section{ABSTRACT}

In this work, the $\mathrm{pH}$ effect on the zinc electrowinning present in the spent pickling baths (SPBs) is analysed with the aim of decreasing the energetic cost of the process. Specifically, the effect of increasing the initial $\mathrm{pH}$ with and without its control during the whole electrolysis experiment is studied on synthetic solutions with concentration values similar to those present in the spent pickling baths. Finally, real SPBs are treated under $\mathrm{pH}$ control and the results obtained are also compared with those acquired with the direct electrolysis of these SPBs in a membrane reactor.

The modification of the initial $\mathrm{pH}$ on synthetic solutions shows an increase in zinc deposition rate as the initial $\mathrm{pH}$ is risen. However, the zinc redissolution phenomenon is present during the whole experiment. On the other hand, when the $\mathrm{pH}$ is controlled, the results obtained are much better as zinc redissolution is prevented and the hydrogen evolution reaction rate is decreased.

Comparing the behaviour between the reactor under $\mathrm{pH}$ control and that in the presence of an anion-exchange membrane, reflects zinc conversion values slightly higher for the membrane reactor due to the zinc precipitation occurring in the reactor under $\mathrm{pH}$ control, which is higher as the $\mathrm{pH}$ rises. However, the specific energy consumption is considerably higher in the membrane reactor mainly due to the ohmic drop introduced by the membrane.

Keywords: deposition, iron, $\mathrm{pH}$ control, precipitation, redissolution, spent-pickling baths, zinc recovery. 


\section{INTRODUCTION}

The oldest technique that uses metallic zinc to protect iron or steel pieces from corrosion is the hot dip galvanizing process [1]. This process is divided into many steps, which basically consist of cleaning the piece surface previously to its immersion into a molten zinc bath. Among these steps, the most polluting one is the pickling process, which is based on dipping the pieces into an $\mathrm{HCl}$ bath that cleans their surface from rust and impurities. Once this bath is spent, it must be treated in order to accomplish the environmental restrictions as the spent pickling baths (SPBs) contain high concentrations of $\mathrm{ZnCl}_{2}$ and $\mathrm{FeCl}_{2}$ in $\mathrm{HCl}$ media [2]. Nowadays, there are many techniques under study that can separate the acid from the salts or concentrate the iron or zinc content of the SPBs [3-8]. However, none of these techniques can bring the zinc present in the baths back into the galvanizing process. Therefore, the use of an electrochemical reactor, where metallic zinc could be deposited on the cathode surface, appears as an interesting alternative.

In previous works, it was concluded that zinc recovery coming from the SPBs was possible by means of an electrochemical reactor but zinc redissolution was observed at high electrolysis time under all the applied experimental conditions [9,10]. This phenomenon is related to the attack of the zinc deposits by the chlorine gas generated at the anode, which is enhanced by the presence of iron [11,12]. As a solution, the authors studied the use of a two compartment reactor separated by means of an anion or a cation exchange membrane $[13,14]$, which avoided the chlorine presence in the cathodic compartment allowing a higher zinc conversion rate. However, this kind of electrochemical reactors increases the cell potential since it boosts both electrode distance and system resistance, which raises the specific energy consumption [15,16]. 
In order to diminish the energetic cost of zinc recovery, different alternatives are suggested. These techniques can permit the use of an undivided reactor, which might reduce the specific energy consumption. The first possibility is to use anode materials, mainly made up of Mn and its alloys with Mo, Sn, W and Fe [17-19], that act as oxygen evolution reaction $\left(2 \cdot \mathrm{H}_{2} \mathrm{O} \rightarrow 4 \cdot \mathrm{H}^{+}+\mathrm{O}_{2}+4 \cdot \mathrm{e}^{-}\right)$catalysts. However, these anode materials present the drawback of the electrocatalyst material degradation [18]. Then, another possibility, which consists of modifying the solution $\mathrm{pH}$, appears as an interesting alternative in order to enhance the oxygen evolution reaction (OER) over the chlorine evolution reaction (CER). The greater the hydroxyl concentration is the faster the OER is and, and the $\mathrm{Z}$ potential of the anode, which is the thermodynamic potential beyond which OER appears, is modified by the $\mathrm{pH}[20,21]$. On the other hand, higher pHs inhibits the CER as the hypochlorite ion formed becomes more stable.

In this sense, the effect of the $\mathrm{pH}$ on the zinc recovery will be evaluated in this paper. More particularly, this work will study the effect of the initial $\mathrm{pH}$ on zinc electrowinning coming from synthetic solutions. In addition, the effect of controlling the $\mathrm{pH}$ for the whole experiment will be also studied. The results of these experiments will be compared with those previously obtained using an electrochemical reactor with and without a membrane. 


\section{MATERIALS AND METHODS}

The electrowinning experiments were performed in an undivided reactor, whose volume was $250 \mathrm{ml}$. Although this reactor is well defined in our previous works $[9,10,13]$, its schematic representation is shown in Fig. 1, which also includes the main reactions for both electrodes. A graphite cathode, titanium DSA anode and Ag/AgCl reference electrode were employed in this reactor. Both cathode and anode were completely immersed in the solutions and symmetrically placed. The cathode consisted of 4 cylindrical graphite bars with an effective area of $28.30 \mathrm{~cm}^{2}$, whereas the anode was made of a titanium mail of $8.8 \mathrm{~cm}^{2}$.

The synthetic solutions were made from analytical grade reagents with concentration values close to those present in the 1:50 diluted SPBs. In these synthetic solutions, $\mathrm{NaCl}$ was added up to $0.1 \mathrm{M}$ to maintain a similar chloride concentration. The SPBs came from a hot dip galvanizer factory and their dilutions were made with distilled water. All experiments were performed at room temperature. The $\mathrm{pH}$ was adjusted using a solution composed of $\mathrm{NaOH} 1 \mathrm{M}$.

Experiments were performed under potentiostatic and galvanostic operation mode. The potential and applied current values selected for the experiments were $-1.75 \mathrm{~V}$ and -450 $\mathrm{mA}$, respectively, in order to compare with the results obtained in previous works. The equipment used for the electrolysis experiments was an Autolab PGSTAT20 potentiostat/galvanostat. Potential, cell voltage, current, $\mathrm{pH}$ and temperature were recorded during the electrowinning. Samples of $0.2 \mathrm{ml}$ were taken from the reactor every $30 \mathrm{~min}$. Zinc and iron determination was performed by atomic absorption spectrophotometry (AAS) as described in our previous works $[9,10,13,14,22]$ in a Perkin-Elmer model Analyst 100 atomic absorption spectrophotometer. 


\section{RESULTS AND DISCUSSION}

As mentioned previously, in the following pages the authors will discuss the effect of modifying or controlling the initial $\mathrm{pH}$ during the whole electrolysis experiment in order to select the best conditions for zinc recovery. Thanks to the record of different experimental variables, such as zinc and iron concentration, $\mathrm{pH}$, electrode potential, etc., the most favourable conditions can be determined by means of the analysis of the figures of merit described ahead [16,23].

The zinc and iron removal rate is determined using Eq. (1):

$$
X(t)=\frac{c_{0}-c(t)}{c_{0}}
$$

where $\mathrm{c}_{0}$ is the initial concentration of zinc or iron present in solution and $\mathrm{c}(\mathrm{t})$ corresponds to the concentration of this species at a given time. On the other hand, the current efficiency, which relates the current used to deposit zinc with the total current input, and is an indicative of the zinc deposition process efficiency, was calculated by using Eq. (2) [24]:

$$
\phi(t)=\frac{n \cdot F \cdot V \cdot\left(c_{0}-c(t)\right)}{\int_{0}^{t} I(t) d t} \cdot 100
$$

where $\mathrm{n}$ is the number of electrons exchanged in the metal deposition, $\mathrm{F}$ is the Faraday's constant, $\mathrm{V}$ is the reactor volume and $\mathrm{I}(\mathrm{t})$ is the applied current at a certain instant of time. 
Finally, the specific energy consumption, which is used to quantify the amount of energy consumed per mass unit of the species of interest deposited on the electrode, was also calculated using the following equation:

$E_{s}(t)=\frac{\int_{0}^{t} U(t) \cdot I(t) d t}{M \cdot V \cdot c_{0} \cdot X(t) \cdot 3600} \quad\left(\mathrm{~kW} \cdot \mathrm{h} \cdot \mathrm{kg}^{-1}\right)$

where $\mathrm{U}(\mathrm{t})$ is the cell potential at a given instant time.

\section{1- Effect of modifying the initial $\mathrm{pH}$ under potentiostatic operation.}

In these experiments, the initial $\mathrm{pH}$ of synthetic solutions was set to values ranging from 1 to 4 and, then, the $\mathrm{pH}$ evolution was recorded. These solutions present zinc and iron concentration values similar to those measured in the 1:50 diluted SPBs. The evolution of zinc fractional conversion $\left(\mathrm{X}_{\mathrm{Zn}}\right)$ for the synthetic solutions under an applied electrode potential of $-1.75 \mathrm{~V}$ is shown in the Fig. 2a). They present a similar behaviour independently of the initial $\mathrm{pH}$ value: an initial $\mathrm{X}_{\mathrm{Zn}}$ increase that begins to decrease after the first 30 or $60 \mathrm{~min}$ of electrolysis. After that decrease, $\mathrm{X}_{\mathrm{Zn}}$ remains practically constant for the rest of the experiment. This decrease in the zinc fractional conversion is associated with the zinc redissolution phenomenon, which is well described in our previous works $[13,14,22]$. It is worth to note that $\mathrm{X}_{\mathrm{Zn}}$ is higher as the initial $\mathrm{pH}$ is increased which is related to a lesser zinc redissolution phenomenon. This effect may be linked to a lesser chlorine generation and/or a lesser amount of free iron, which acts as catalyst of the zinc redissolution phenomenon. 
Regarding the evolution of the $\mathrm{pH}$ values, Fig. 2b), it is worth to mention that they tend to values close to 2 for all the cases under study. This trend was also observed in our previous works $[13,14,22,25,26]$, in which when the $\mathrm{pH}$ reached this value the iron codeposition started. However, in this case iron co-deposition is not observed in any case under study since the zinc concentration has not diminished sufficiently so as to permit iron co-deposition.

Moreover, in all the cases presented in Fig. 2b), the $\mathrm{pH}$ tends to 2 from the first instants of the electrolysis and remains close to this value until the end of the electrolysis. This fact is related to the equilibrium between the reactions taking place at the electrodes: the protons generation and consumption caused by both the oxygen and the hydrogen evolution reactions, which maintains the solution $\mathrm{pH}$ practically constant. These experiments were also carried out working in galvanostatic operation mode under an applied current of $-450 \mathrm{~mA}$ and the same conclusions can be extracted from the results obtained.

\section{2- Effect of controlling the $\mathrm{pH}$ under potentiostatic operation.}

Since, as shown in the previous point, the modification of the initial $\mathrm{pH}$ does not avoid the zinc redissolution phenomenon, in this case the $\mathrm{pH}$ was not only modified before the electrolysis started but it was also maintained in a range of $\pm 0.25 \mathrm{pH}$ units from the desired value by means of the addition of a $\mathrm{NaOH} 1 \mathrm{M}$ solution. In this point, the same synthetic solutions as those previously presented are analysed. The experiments were also carried out at $-1.75 \mathrm{~V}$ and the results were compared with those obtained for the unmodified-pH solution, whose $\mathrm{pH}$ value is around 1. 
Fig. 3a) illustrates the evolution with time of the zinc fractional conversion as a function of the solution $\mathrm{pH}$. In this case, the zinc conversion obtained is practically the same independently of the solution $\mathrm{pH}$ with the exception of the uncontrolled-pH solution, which presents lower values since zinc redissolution is present practically from the beginning of the experiment. This phenomenon is not observed for the synthetic solutions under $\mathrm{pH}$ control, which is linked to the higher $\mathrm{pH}$ values of these solutions during the whole electrolysis experiments. From the speciation diagram depicted in Fig. 4, it can be observed that at $\mathrm{pH}$ values under $3, \mathrm{Cl}_{2}$ is the predominant species but when the $\mathrm{pH}$ is between 3 and 6, the principal chlorine compound is $\mathrm{HClO}$. This change in the chlorine main species may decrease the zinc redissolution rate as this phenomenon seems to be caused only by the chlorine gas present in the solution since is a stronger oxidant. In addition, the enhancement of the OER over the CER due to both the higher hydroxyl concentration and the change in the $\mathrm{Z}$ potential of the anode to less anodic values, may be another detrimental factor for the chlorine generation responsible for the zinc redissolution phenomenon [21,27]. Finally, it is worth to note that increasing the $\mathrm{pH}$ value from 3 to 5 in the synthetic solutions does not improve the obtained results.

During the electrolysis experiments the measurement of iron concentration was very difficult because of the formation of iron precipitates that can form floccules and cause inaccuracies in the measurement. Therefore, once finished the experiment, the solution was led without stirring for $30 \mathrm{~min}$ in order to permit the floccule precipitation. Later a sample of the supernatant was taken to measure both zinc and iron concentration in solution. Then, the solution was acidified to a $\mathrm{pH}$ value lesser than 1 and, after this, another sample was taken to determine both zinc and iron amount that had precipitated. In addition, to calculate both iron and zinc deposition, the cathode was cleaned with distilled water and, afterwards, it was dipped into $100 \mathrm{ml}$ of $\mathrm{HCl} 0.1 \mathrm{M}$ until the 
complete deposit dissolution. The fraction of final iron and zinc that precipitates in each experiment was determined with the following expression:

$$
X_{\text {prec }}=\frac{c_{f}-c_{s}}{c_{0}}
$$

where $\mathrm{C} f_{\mathrm{f}}$ is the concentration value obtained after acidifying the solution and $\mathrm{c}_{\mathrm{s}}$ is the supernatant concentration value.

All the results obtained are presented in Table 1. The first conclusion extracted is that iron deposition does not reach the $10 \%$ in any case studied. This fact differs significantly regarding the results obtained in our previous works $[13,14,22,25,26]$, in which when zinc concentration in solution had diminished considerably and when the $\mathrm{pH}$ reached a value close to 2 , iron co-deposition started and reached values close to $100 \%$. The behaviour observed in this table for the controlled-pH solutions may be explained in terms of two different phenomena. On one hand, an increase in $\mathrm{pH}$ leads to a higher iron precipitation, and consequently, the iron co-deposited diminished. And on the other hand, the increase in $\mathrm{pH}$ enhances the zinc hydroxide formation on the cathode surface which is responsible for the inhibition of the iron deposition. This phenomenon is known as anomalous co-deposition: the zinc-iron system does not follow a normal deposition process, that is, as a function of their reduction potential but they follow an anomalous co-deposition process [28-30], where zinc deposits preferentially over iron. This process consists of $\mathrm{Zn}(\mathrm{OH})_{2}$ formation, thanks to the local $\mathrm{pH}$ increase due to HER, as a previous step to zinc deposition, which forms a film around the cathode surface that inhibits iron deposition. However, this film is usually broken when zinc concentration decreases sufficiently and iron begins to co-deposit. Therefore, it is 
possible that the control of the $\mathrm{pH}$ on the solutions may allow the continuous $\mathrm{Zn}(\mathrm{OH})_{2}$ formation as a consequence of the higher hydroxyl concentration in the solution.

Regarding the effect of controlling the $\mathrm{pH}$ in the current evolution with time, Fig. 5, it is worth to note that an increase in the $\mathrm{pH}$ leads to a decrease in the current value. Furthermore, the initial increase in the current values with time related to the zinc nucleation on the cathode is negligible when the $\mathrm{pH}$ is controlled, presenting a decreasing trend in all the cases. This change in the tendency is associated with the decrease of the contribution of the HER caused by the higher $\mathrm{pH}$. A deeper analysis shows that the applied current presents the greatest decrease with time for the highest $\mathrm{pH}$ solution value $(\mathrm{pH}=5)$ since the effect of the HER is minimum in this case, which can only be related to the zinc depletion from solution. This higher hydroxyl concentration may enhance the formation of $\mathrm{Zn}(\mathrm{OH})_{2}$ that Dahms et al. suggests as a prior step for zinc deposition [31], and this zinc hydroxide may compete with $\mathrm{H}^{+}$for the active sites on the cathode surface, which can be also associated with the current decrease. On the other hand, the differences in the current values amongst the experiments under $\mathrm{pH} 3$ and 4 are smaller than the differences between them and the experiment beneath $\mathrm{pH}$ 5. This fact may be caused by a change in the proton source for the HER since near neutral $\mathrm{pH}$ the proton source is, directly, $\mathrm{H}_{2} \mathrm{O}[32,33]$, which origins a decrease in the kinetics and, then, in its contribution to the total current.

Fig. 6 shows the evolution of the zinc current efficiency with time for all the solutions mentioned above. The values obtained for the uncontrolled-pH solution, are the lowest because of the greater contribution of the HER to the total current from the beginning of the experiment together with the zinc redissolution phenomenon. For the controlled-pH solutions, almost all the current applied during the initial electrolysis instants is used to deposit zinc. Once a high zinc amount is removed from the solution, zinc current 
efficiency begins to decrease as the parallel reactions, HER and iron deposition, become more important. It is worth to note that for the experiment with the higher $\mathrm{pH}$ value, the current efficiency is considerably higher. This is associated with the change in the proton source mentioned previously. Therefore, controlling the $\mathrm{pH}$ for the whole electrolysis experiments allows obtaining higher current efficiency values, up to 5 times higher than those reached treating the solutions without $\mathrm{pH}$ control.

Fig. 7 presents the zinc specific energy consumption evolution with time for the same solutions presented above. In all the cases under study, the specific energy consumption increases since zinc is depleted from solution, as expected $[9,13]$. Although the reactor is the same, the minor importance of HER in the experiments with controlled $\mathrm{pH}$ make their energy consumption values up to two magnitude orders lesser than those obtained for the uncontrolled-pH solution. Under $\mathrm{pH}$ control, a little influence of the solution $\mathrm{pH}$ is observed and can be associated with the decrease in the protons concentration and, consequently, in the HER rate and, also with the change in the proton source for the HER, as mentioned above. Therefore, the use of a reactor with $\mathrm{pH}$ control seems as an interesting alternative to reduce significantly the energetic costs of the treatment.

3.3- Comparison amongst the reactor under $p H$ control and a membrane reactor treating the diluted spent pickling baths.

Once seen the benefits of controlling the solution $\mathrm{pH}$ for the whole electrolysis experiment, it seems necessary to compare the behaviour of this reactor with the results obtained using an electrochemical membrane reactor in the presence of an anionexchange membrane (RAEM) that also eliminates the zinc redissolution phenomenon $[13,14,22]$. In this point, the experiments were made treating the 1:50 diluted SPBs in both reactors and were carried out under galvanostatic operation (-450 mA) since this 
operation mode is the one used at an industry scale [10,15]. Finally, the controlled pH ranged from 3 to 5 .

Fig. 8 shows the evolution of zinc fractional conversion (a)) and $\mathrm{pH}(\mathrm{b})$ ) with time for the experimental conditions explained above. As expected, during the first 120 min the obtained results are very similar since both reactors avoid the zinc redissolution phenomenon and the applied current is the same. However, from this moment, the results obtained for $\mathrm{pH} 5$ follow a different tend: $\mathrm{X}_{\mathrm{Zn}}$ remains practically constant in a value close to 0.7 . In addition, the results obtained with $\mathrm{pH} 3$ shows a similar behaviour beyond 180 min with a zinc conversion values near to 0.85 . Therefore, when the $\mathrm{pH}$ is controlled a maximum conversion value is obtained which grows as the $\mathrm{pH}$ value diminishes. This phenomenon is not due to zinc redissolution but to the zinc coprecipitation into the iron floccule formed as a consequence of the increase of the solution $\mathrm{pH}$. This fact was corroborated at the end of both experiments where the solution was let in rest 30 min and, afterwards zinc and iron concentration were measured in the supernatant and the precipitate, which showed that part of the zinc was swept along by $\mathrm{Fe}(\mathrm{OH})_{3}$.

With regard to the $\mathrm{pH}$ evolution in the RAEM, it initially increases due to HER up to values close to 2, which permits iron co-deposition, from which it remains practically constant. As expected, for the reactors under $\mathrm{pH}$ control, the $\mathrm{pH}$ remains at the desired value.

As mentioned above, the control of the $\mathrm{pH}$ causes the formation of iron floccules that affects the measurement of iron concentration. Then, the same procedure as that explained in the previous point was carried out, that is, once the experiment has ended, the dissolution was kept, first, without stirring for $30 \mathrm{~min}$ in order to precipitate the 
floccules and a measure from the supernatant was taken. Then the solution was acidified in order to redissolve both iron and zinc present in the precipitate, and another sample was taken. These samples were measured by AAS and Eq. (4) was also used to calculate the fraction of iron and zinc that precipitates.

In this case, there are three different results that are presented in Table 2. On one hand, the RAEM presents practically the complete zinc and iron deposition. On the other hand, when the $\mathrm{pH}$ is controlled on 3, iron deposition is also detected but its conversion has practically diminished 4 times, which is associated with the formation of floccules of iron hydroxide. It is worth to note that zinc was partially swept along by the iron floccules, which explains the maximum on zinc deposition observed previously in Fig. 8. Finally, for the experiment under a $\mathrm{pH}$ of 5 , iron deposition does not reach the $10 \%$. This fact is related to the lack of free iron cations as almost all the iron has precipitated. This suggests that iron deposition also can reach a maximum value that decrease as the $\mathrm{pH}$ is increased. Besides, the same conclusion can be extracted for zinc deposition: the higher the $\mathrm{pH}$ the higher the zinc precipitation, and the lower the zinc deposition is.

On the other hand, if Tables 1 and 2 are compared, it can be seen that they present different results, especially with regard to zinc precipitation, which is only observed in Table 2. This fact is related to the current applied in each operation mode. In the potentiostatic experiments, the applied current is, approximately, four times lower than those applied in the galvanostatic mode. This higher applied current increases the hydroxyl generation as a consequence of HER responsible for the zinc hydroxide formation. Furthermore, this parallel reaction will be enhanced as zinc is depleted from solution and the applied current becomes higher than the limiting one. 
Finally, the evolution of the zinc specific energy consumption for all the experiments mentioned above is presented in Fig. 9. In this case, the use of an undivided reactor under $\mathrm{pH}$ control presents lower values of $\mathrm{E}_{\mathrm{s}}$ than those obtained in the membrane reactor due to the electrical resistance introduced by the membrane together with the higher separation between the electrodes that generates an increase in the cell potential, (see inset Figure), and, therefore, in the amount of energy consumed to recover zinc. Therefore, the use of an undivided reactor under $\mathrm{pH}$ control presents a lower energetic cost. Amongst the values obtained in the undivided reactor, their differences are related to the higher zinc co-precipitation for the experiment at $\mathrm{pH} 5$ explained before. The evolution of this parameter with time for any of the cases shown is well reported in the explanation of Fig. 7.

With regards to the cell potential evolution of these experiments, inset of Fig.9, it starts at a high value due to the higher electrode resistance to zinc deposition. Afterwards, $U$ diminishes due to the zinc nucleation on the electrode up to a minimum value from which $U$ begins to increase during the rest of the electrolysis as a consequence of the greater importance of parallel reactions and the removal of ions (zinc and iron) from solution. In the case of the controlled-pH experiments, this increase is practically negligible since more ions, in form of $\mathrm{NaOH}$, are continuously added to the solution, which avoids the ohmic drop increase. The differences observed amongst the two controlled $\mathrm{pH}$ values are associated with the minor solution conductivity of the $\mathrm{pH} 5$ solution as a consequence of the greater amount of iron floccules formed. 


\section{CONCLUSIONS}

Synthetic solutions with similar composition to that of the 1:50 diluted spent pickling baths (SPBs) and different initial $\mathrm{pH}$ values, from 1 to 4 , were prepared in order to study the zinc recovery by means of electrolysis. In this case, the initial $\mathrm{pH}$ modification slightly improved the zinc recovery during the first instants of electrolysis since the zinc redissolution phenomenon was only avoided during these instant times.

Then, the electrolysis of synthetic solutions under $\mathrm{pH}$ control was carried out under both potentiostatic and galvanostatic operation. In these experiments, the zinc redissolution phenomenon was avoided since the oxygen evolution reaction (OER) was enhanced over the chlorine evolution reaction (CER) and also due to the fact that for $\mathrm{pH}$ values beyond 3, hypochlorite is the main chloride compound instead of chlorine, being this latter responsible for the zinc redissolution phenomenon together with iron. In addition, both the current efficiency and the specific energy consumption were improved since the higher the $\mathrm{pH}$ the lower the hydrogen evolution reaction (HER). With regard to iron co-deposition, its fractional conversion did not reach the $10 \%$ in any experiment. This fact was related to the continuous increase of the hydroxyl concentration that favours the iron hydroxide precipitation, and avoids the breaking of the $\mathrm{Zn}(\mathrm{OH})_{2}$ film that enhances the zinc deposition over the iron one due to the anomalous co-deposition phenomenon.

Comparing the results under $\mathrm{pH}$ control with those obtained using a membrane reactor (RAEM) when treating the diluted spent pickling baths, it is inferred that the zinc redissolution phenomenon was prevented in both cases and high zinc fractional conversion values were obtained. Nevertheless, iron precipitation was observed in the experiments under $\mathrm{pH}$ control due to increase of the solution $\mathrm{pH}$ and, as a consequence, zinc was co-precipitated together with iron, which avoided the complete recovery of 
zinc. Consequently, as the $\mathrm{pH}$ was increased the zinc and iron amount recovered decreased. However, the specific energy consumption showed much lower values, practically $50 \%$, for the reactor under $\mathrm{pH}$ control due to the ohmic drop introduced by the membrane, and since the higher $\mathrm{pH}$ values recorded under $\mathrm{pH}$ control diminished the importance of parallel reactions.

Therefore, the use of an undivided reactor with a $\mathrm{pH}$ control seems an interesting alternative to optimize the treatment of the SPBs, since although a small amount of zinc can be precipitated together with iron, setting the $\mathrm{pH}$ value around 3 leads to high values of zinc recovered together with low energetic costs and iron co-deposition. 


\section{REFERENCES}

[1] A.R. Marder, The metallurgy of zinc-coated steel, Prog. Mater. Sci. 45 (2000) $191-271$.

[2] U. Kerney, Treatment of spent pickling acids from hot dip galvanizing, Resour. Conserv. Recy. 10 (1994) 145-151.

[3] C. Stocks, J. Wood, S. Guy, Minimisation and recycling of spent acid wastes from galvanizing plants, Resour. Conserv. Recycl. 44 (2005) 153-166.

[4] M. Regel-Rosocka, A review on methods of regeneration of spent pickling solutions from steel processing, J. Hazard. Mater. 177 (2010) 57-69.

[5] G. Csicsovszki, T. Kékesi, T.I. Török, Selective recovery of Zn and Fe from spent pickling solutions by the combination of anion exchange and membrane electrowinning techniques, Hydrometallurgy. 77 (2005) 19-28.

[6] J.A. Carrera, E. Bringas, M.F.S. Román, I. Ortiz, Selective membrane alternative to the recovery of zinc from hot-dip galvanizing effluents, J. Memb. Sci. 326 (2009) 672-680.

[7] J.A. Carrera, E. Muñoz, E. Bringas, M.F. San Román, I. Ortiz, Influence of operation variables on the recovery of zinc from spent pickling effluents using the emulsion pertraction technology, Desalination. 245 (2009) 675-679.

[8] A. Urtiaga, E. Bringas, R. Mediavilla, I. Ortiz, The role of liquid membranes in the selective separation and recovery of zinc for the regeneration of $\operatorname{Cr}(\mathrm{III})$ passivation baths, J. Memb. Sci. 356 (2010) 88-95.

[9] J. Carrillo-Abad, M. García-Gabaldón, E. Ortega, V. Pérez-Herranz, Electrochemical recovery of zinc from the spent pickling baths coming from the hot dip galvanizing industry. Potentiostatic operation, Sep. Purif. Technol. 81 
(2011) 200-207.

[10] J. Carrillo-Abad, M. García-Gabaldón, V. Pérez-Herranz, Electrochemical recovery of zinc from the spent pickling solutions coming from hot dip galvanizing industries. Galvanostatic operation, Int. J. Electrochem. Sci. 7 (2012) $5442-5456$.

[11] O. Caldwell-Ralston, Electrolytic Deposition and Hydrometallurgy of Zinc, McGraw-Hill Book Company Inc., New York, 1921.

[12] D. J.Fray, B. K.Thomas, Zinc Chloride Electrolyses, 1981. Patent Number: US4292147.

[13] J. Carrillo-Abad, M. García-Gabaldón, E. Ortega, V. Pérez-Herranz, Recovery of zinc from spent pickling solutions using an electrochemical reactor in presence and absence of an anion-exchange membrane: Galvanostatic operation, Sep. Purif. Technol. 98 (2012) 366-374.

[14] J. Carrillo-Abad, M. García-Gabaldón, V. Pérez-Herranz, Study of the zinc recovery from spent pickling baths by means of an electrochemical membrane reactor using a cation-exchange membrane under galvanostatic control, Sep. Purif. Technol. 132 (2014) 479-486.

[15] M. García-Gabaldón, V. Pérez-Herranz, J. García-Antón, J.L. Guiñón, Electrochemical recovery of tin from the activating solutions of the electroless plating of polymers: Galvanostatic operation, Sep. Purif. Technol. 51 (2006) 143-149.

[16] V. Pérez-Herranz, J.L. Guiñón, J. García-Antón, Ingeniería Electroquímica, Servicio de Publicaciones de la Universitat Politècnica de València, València, 1997.

[17] N.A. Abdel Ghany, N. Kumagai, S. Meguro, K. Asami, K. Hashimoto, Oxygen 
evolution anodes composed of anodically deposited Mn-Mo-Fe oxides for seawater electrolysis, Electrochim. Acta. 48 (2002) 21-28.

[18] Z. Kato, J. Bhattarai, N. Kumagai, K. Izumiya, K. Hashimoto, Durability enhancement and degradation of oxygen evolution anodes in seawater electrolysis for hydrogen production, Appl. Surf. Sci. 257 (2011) 8230-8236.

[19] V. Petrykin, K. MacOunová, M. Okube, S. Mukerjee, P. Krtil, Local structure of Co doped RuO2 nanocrystalline electrocatalytic materials for chlorine and oxygen evolution, Catal. Today. 202 (2013) 63-69.

[20] J. Bennett, Electrodes for generation of hydrogen and oxygen from seawater, Int. J. Hydrogen Energy. 5 (1980) 401-408.

[21] H. Selcuk, M. a. Anderson, Effect of $\mathrm{pH}$, charge separation and oxygen concentration in photoelectrocatalytic systems: Active chlorine production and chlorate formation, Desalination. 176 (2005) 219-227.

[22] J. Carrillo-abad, I. Ortiz-gandara, E. Bringas, A. Miren, I. Ortiz, V. Perezherranz, Selective recovery of zinc from spent pickling baths by the combination of membrane-based solvent extraction and electrowinning technologies, Sep. Purif. Technol. 151 (2015) 232-242.

[23] M. García-Gabaldón, V. Pérez-Herranz, J. García-Antón, J.L. Guiñón, Electrochemical recovery of tin and palladium from the activating solutions of the electroless plating of polymers: Potentiostatic operation, Sep. Purif. Technol. 45 (2005) 183-191.

[24] S. Koter, A. Narebska, Current Efficiency and Transport Phenomena in Systems with Charged Membranes, Sep. Sci. Technol. 24 (1989) 1337-1354.

[25] M. García-Gabaldón, J. Carrillo-Abad, E. Ortega-Navarro, V. Pérez-Herranz, Electrochemical study of a simulated spent pickling solution, Int. J. Electrochem. 
Sci. 6 (2011) 506-519.

[26] J. Carrillo-Abad, M. García-Gabaldón, V. Pérez-Herranz, Treatment of spent pickling baths coming from hot dip galvanizing by means of an electrochemical membrane reactor, Desalination. (2014).

[27] R. Balaji, B.S. Kannan, J. Lakshmi, N. Senthil, S. Vasudevan, G. Sozhan, et al., An alternative approach to selective sea water oxidation for hydrogen production, Electrochem. Commun. 11 (2009) 1700-1702.

[28] E. Gómez, E. Peláez, E. Valle, Electrodeposition of zinc + iron alloys I . Analysis of the initial stages of the anomalous codeposition, J. Electroanal. Chem. 469 (1999) 139-149.

[29] Z. Zhang, W.H. Leng, H.B. Shao, J.Q. Zhang, J.M. Wang, C.N. Cao, Study on the behavior of Zn-Fe alloy electroplating, J. Electroanal. Chem. 516 (2001) 127130.

[30] Z.N. Yang, Z. Zhang, J.Q. Zhang, Electrodeposition of decorative and protective Zn-Fe coating onto low-carbon steel substrate, Surf. Coatings Technol. 200 (2006) 4810-4815.

[31] H. Dahms, I.M. Croll, The Anomalous Codeposition of Iron-Nickel Alloys, J. Electrochem. Soc. 112 (1965) 771-775.

[32] Y.F. Cheng, L. Niu, Mechanism for hydrogen evolution reaction on pipeline steel in near-neutral pH solution, 9 (2007) 558-562.

[33] B.E. Conway, B. V Tilak, Interfacial processes in v ol v ing electrocatalytic e v olution and oxidation of $\mathrm{H} 2$, and the role of chemisorbed H, 47 (2002). 


\section{Figures and Tables}

Fig. 1: Schematic representation of the electrochemical reactor used.

Fig. 2. Evolution of zinc fractional conversion, a), and $\mathrm{pH}, \mathrm{b}$ ), with time as a function of the initial $\mathrm{pH}$. Potentiostatic operation at $-1.75 \mathrm{~V}$.

Fig. 3. Evolution of zinc fractional conversion, a), and $\mathrm{pH}, \mathrm{b}$ ), with time as a function of the solution $\mathrm{pH}$. Potentiostatic operation at $-1.75 \mathrm{~V}$.

Fig. 4. Speciation diagram for chlorine species. $\mathrm{C}_{0}=1 \mathrm{M}$.

Fig. 5. Evolution of current with time as a function of the solution pH. Potentiostatic operation at $-1.75 \mathrm{~V}$.

Fig. 6. Evolution of zinc current efficiency with time as a function of the solution $\mathrm{pH}$. Potentiostatic operation at $-1.75 \mathrm{~V}$.

Fig. 7. Evolution of zinc specific energy consumption with time as a function of the solution $\mathrm{pH}$. Potentiostatic operation at $-1.75 \mathrm{~V}$.

Fig. 8. Evolution of zinc fractional conversion a) and $\mathrm{pH}$ b) with time as a function of the solution $\mathrm{pH}$. Galvanostatic operation at $-450 \mathrm{~mA}$.

Fig. 9. Evolution of zinc specific energy consumption and cell potential (inset Fig.) with time as a function of the solution $\mathrm{pH}$. Galvanostatic operation at $-450 \mathrm{~mA}$.

Table 1. Iron conversion and precipitation rate as a function of the solution $\mathrm{pH}$. Potentiostatic operation at $-1.75 \mathrm{~V}$.

Table 2. Zinc and iron conversion rate, and zinc and iron precipitation rate as a function of the solution $\mathrm{pH}$. Galvanostatic operation at $-450 \mathrm{~mA}$. 


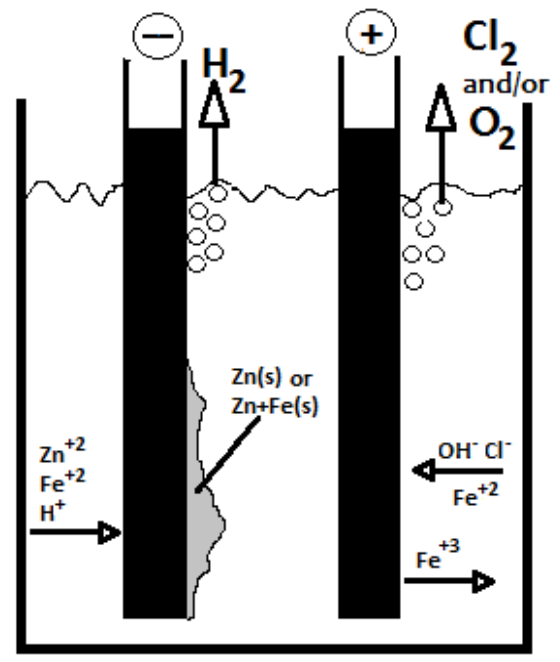

Figure 1 

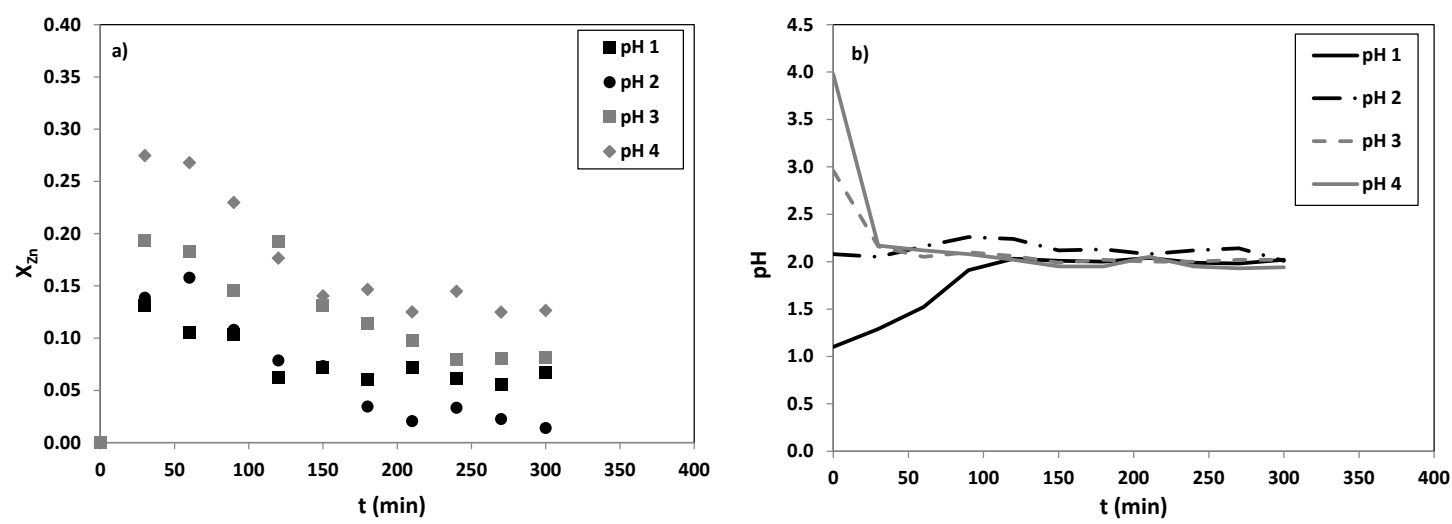

Figure 2 

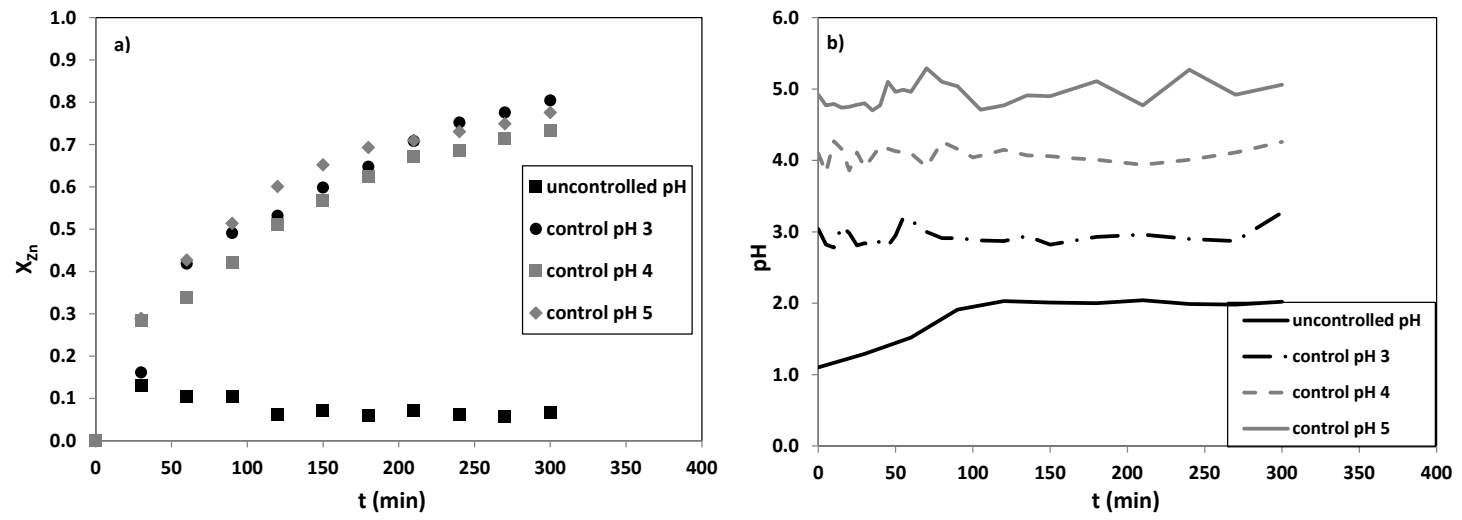

Figure 3 


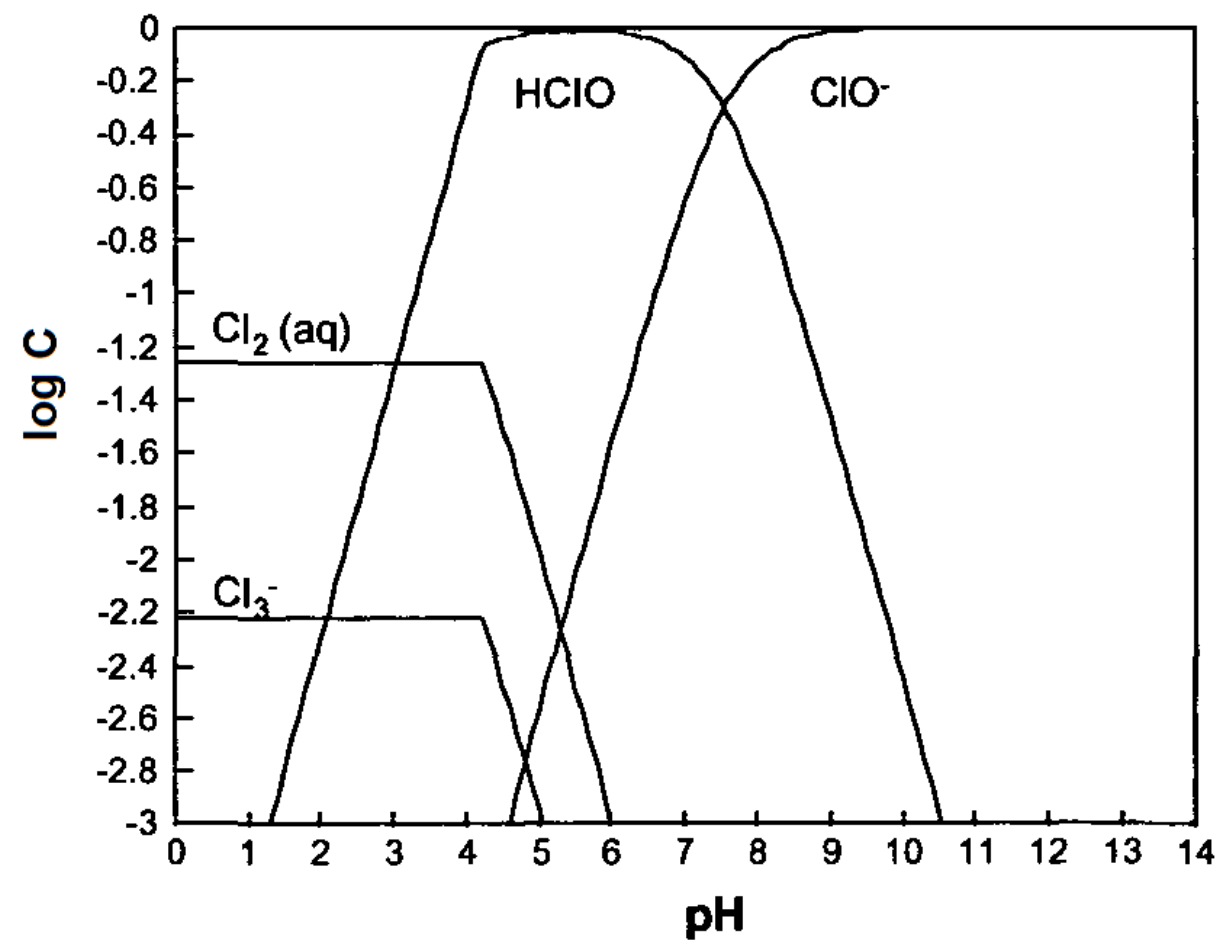

Figure 4 


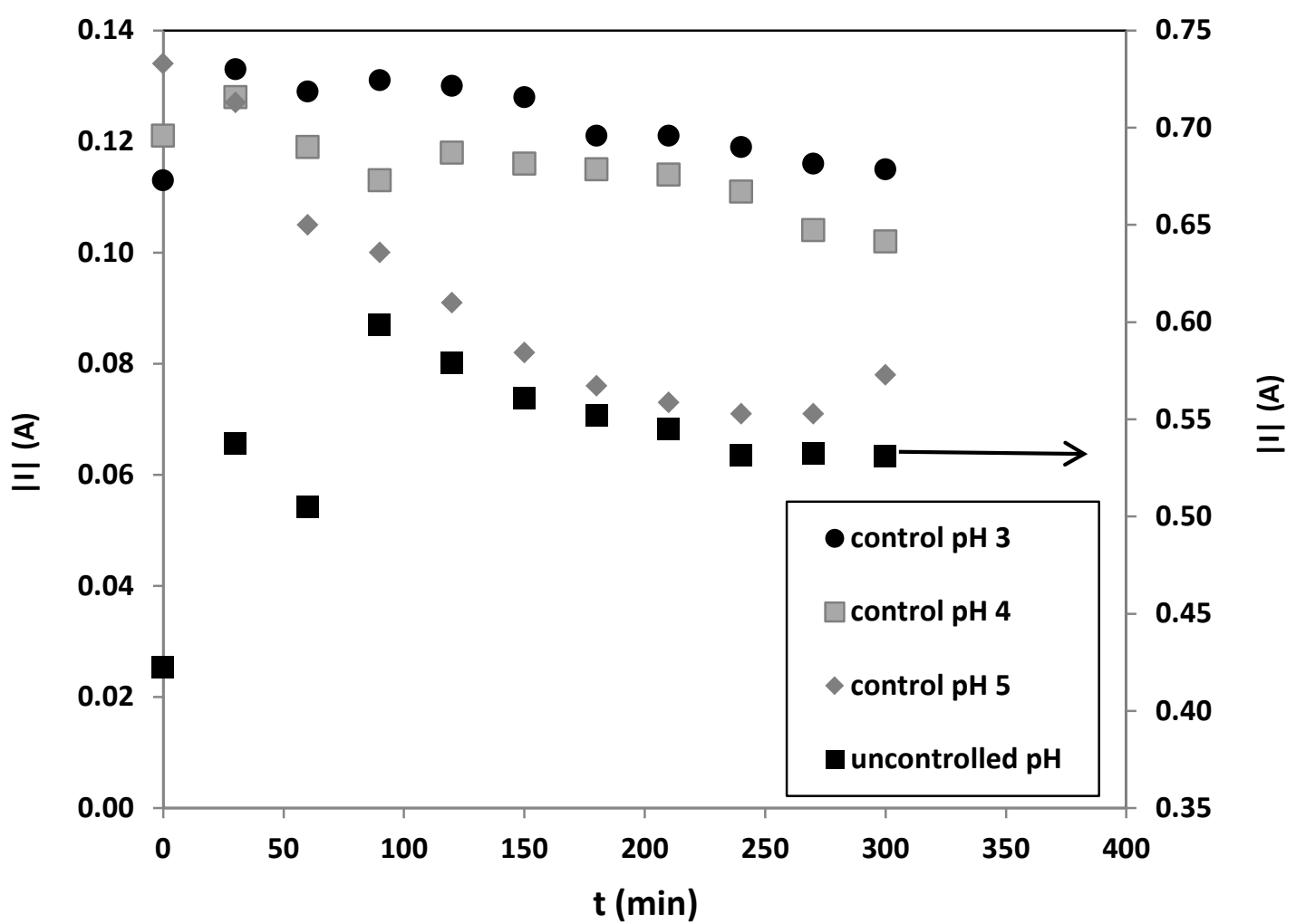

Figure 5 


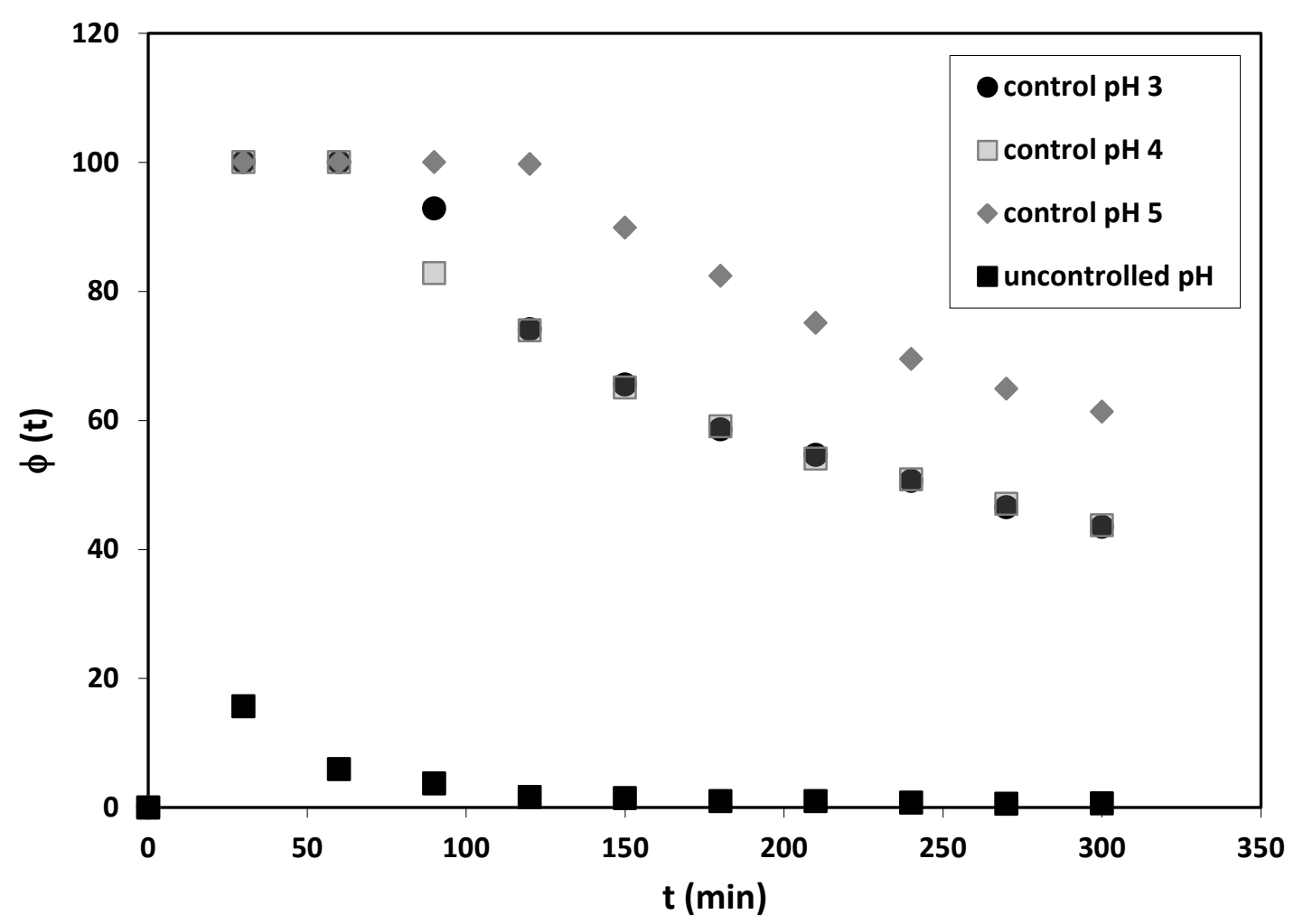

Figure 6 


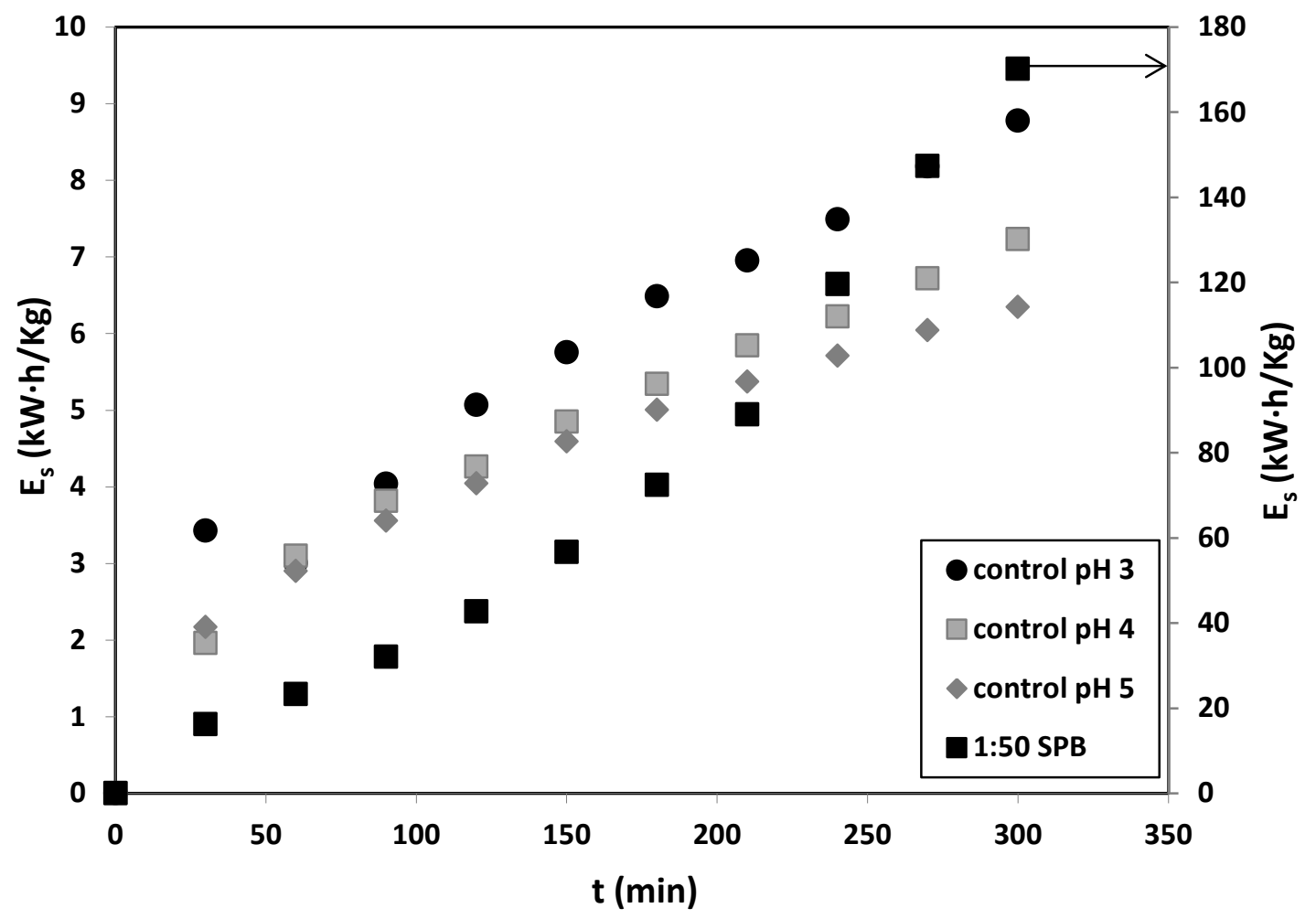

Figure 7 

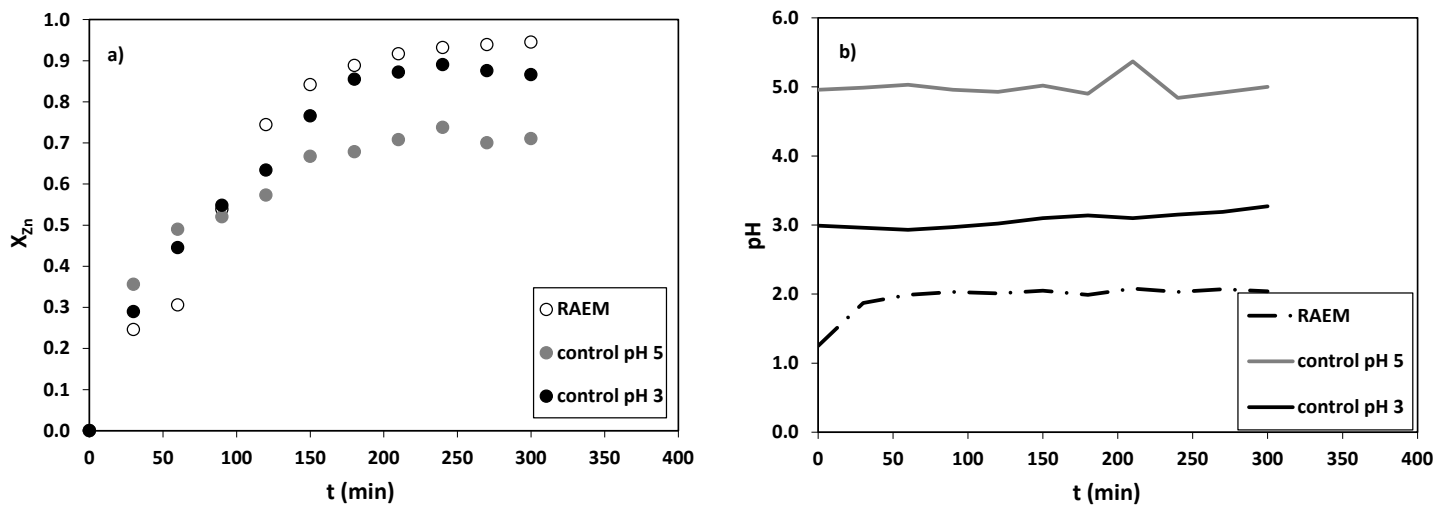

Figure 8 


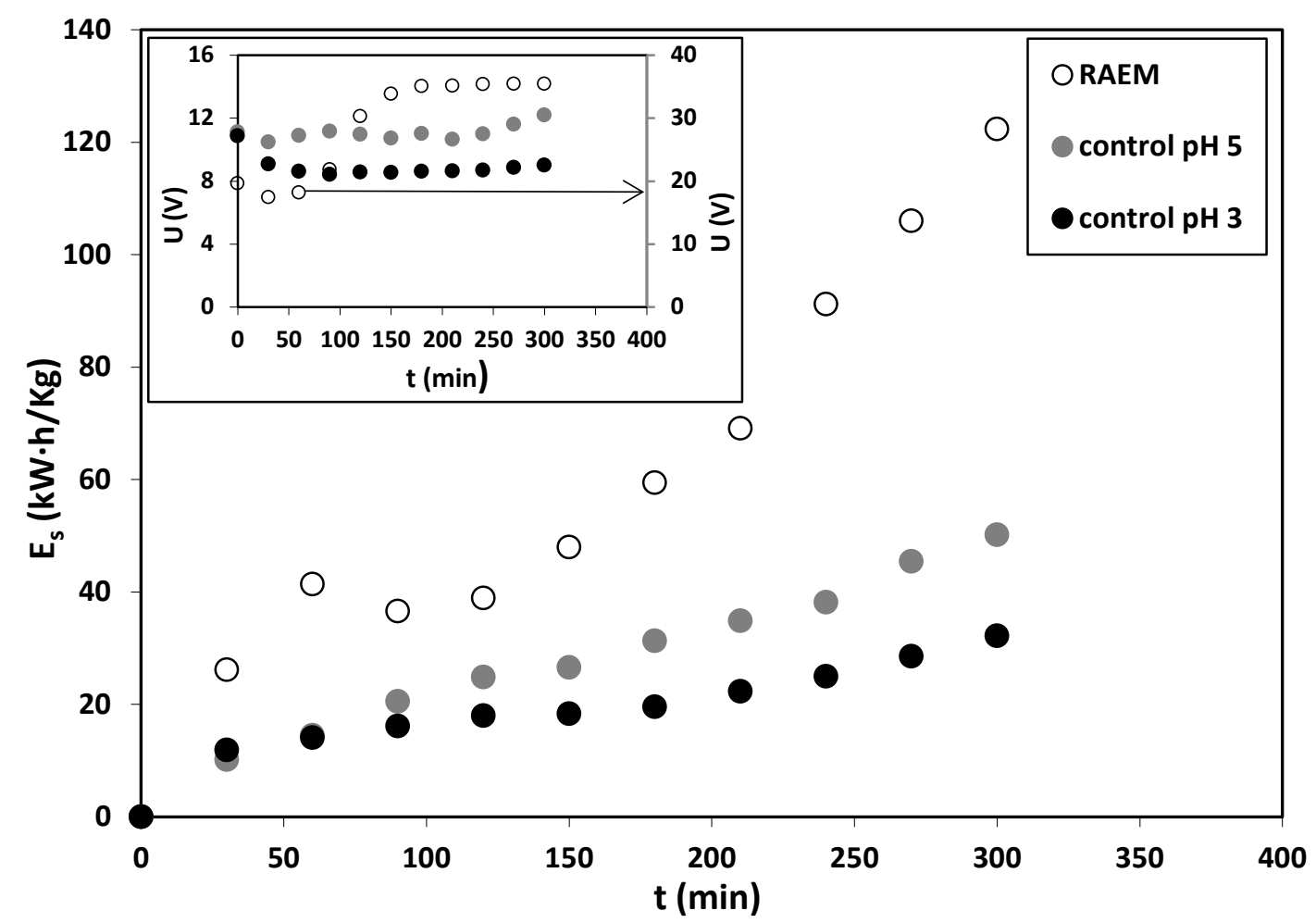

Figure 9 
Table 1

\begin{tabular}{|l|c|c|}
\hline Solution & $\mathrm{X}_{\mathrm{Fe}}$ dep. & $\mathrm{X}_{\mathrm{Fe}}$ prec. \\
\hline Uncontrolled pH & 0 & 0 \\
\hline $\mathrm{pH} \mathrm{3}$ & 0.087 & 0.205 \\
\hline $\mathrm{pH} 4$ & 0.072 & 0.097 \\
\hline $\mathrm{pH} \mathrm{5}$ & 0.098 & 0.118 \\
\hline
\end{tabular}


Table 2

\begin{tabular}{|l|c|c|c|c|}
\hline Solution & $\mathrm{X}_{\mathrm{Fe}}$ dep & $\mathrm{X}_{\mathrm{Fe}}$ prec & $\mathrm{X}_{\text {Zn }}$ dep & $\mathrm{X}_{\text {Zn }}$ prec \\
\hline RAEM & 0.994 & --- & 0.945 & --- \\
\hline pH 3 & 0.253 & 0.350 & 0.876 & 0.088 \\
\hline pH 5 & 0.098 & 0.887 & 0.714 & 0.206 \\
\hline
\end{tabular}

